\title{
Heterotopic ossification in a patient with paroxysmal sympathetic hyperactivity following multiple trauma complicated with vitamin D deficiency: a case report
}

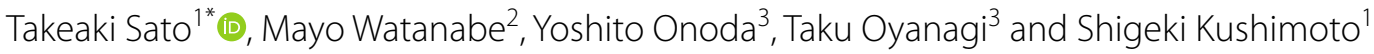

\begin{abstract}
Background: Paroxysmal sympathetic hyperactivity (PSH) may occur in patients with traumatic brain injury. Heterotopic ossification (HO) has frequently been observed in patients with PSH and has been found to impair patients' recoveries. However, the pathophysiology of $\mathrm{HO}$ in patients with PSH remains unelucidated. Vitamin D deficiency is a common abnormality among critically ill patients and may be associated not only with musculoskeletal complications, but also with high morbidity and mortality. The association between vitamin D deficiency and $\mathrm{HO}$ in patients with PSH has not yet been evaluated.
\end{abstract}

Case presentation: A 21-year-old man was in a motorcycle accident. The initial diagnosis was diffused axonal injury, thoracic aortic injury, bilateral lung contusion with hemopneumothorax, liver injury, vertebral injury of T5, along with fractures of the right humerus, left patella, bilateral scapula, and a stable pelvic fracture, with an Injury Severity Score of 50. Two weeks after admission, he was diagnosed with PSH. One month after the injury, decreased joint mobility and progressive pain were evident. Computed tomography (CT) showed HO in his humerus, ulna, radius, scapula, ilium, pubis, ischium, knee joint, patella, and tibia, as well as renal calculus. To evaluate metabolic bone abnormalities, we measured levels of $25-\mathrm{OH}$ vitamin $\mathrm{D}$, parathyroid hormone, calcitonin, procollagen type I N-terminal propeptide (a marker of bone formation), and tartrate-resistant acid phosphatase $5 \mathrm{~b}$ (a marker of bone resorption). This revealed a vitamin D deficiency. Bisphosphonate agents and vitamin D were administered for 1 month. Thereafter, his symptoms, radiographic findings, and laboratory abnormalities improved, and he was transferred to another facility.

Conclusions: $\mathrm{HO}$ in patients with PSH, following severe head injury, may be associated with vitamin D deficiency. Medication for vitamin-D-related metabolism abnormalities may represent a novel intervention for $\mathrm{HO}$ with PSH.

Keywords: Heterotopic ossification, Paroxysmal sympathetic hyperactivity, Vitamin D deficiency

\section{Background}

In patients with traumatic brain injury, an excessive response of the autonomic nervous system may occur, which is defined as paroxysmal sympathetic hyperactivity

\footnotetext{
*Correspondence: takeaki@med.tohoku.ac.jp

${ }^{1}$ Department of Emergency and Critical Care Medicine, Tohoku University Hospital Emergency Center, 1-1 Seiryo-cho, Aoba-ku, Sendai-shi 980-8754, Japan

Full list of author information is available at the end of the article
}

(PSH) [1]. Heterotopic ossification (HO) is the presence of lamellar bone in soft tissue, where normally bone does not exist [2]. $\mathrm{HO}$ is frequently observed in patients with musculoskeletal trauma, spinal cord injury, and central nervous system injury [3]. HO occurs as a complication in patients with PSH and is considered a diagnostic criterion [4]. However, the pathophysiology of $\mathrm{HO}$ in patients with PSH has not been elucidated.

Vitamin D deficiency is commonly seen in critically ill patients, and may be associated with musculoskeletal 
complications as well as high morbidity and mortality [5]. However, the association between vitamin D deficiency and $\mathrm{HO}$ in patients with $\mathrm{PSH}$ has not been evaluated.

Here, we report a case of multiple instances of $\mathrm{HO}$ in a patient with $\mathrm{PSH}$, following severe head injury and an associated vitamin D deficiency.

\section{Case presentation}

A 21-year-old male, who was in a motorcycle accident, presented with a confused level of consciousness and had a Glasgow Coma Scale score of E3V4M5. His blood pressure was $58 / 34 \mathrm{mmHg}$, his heart rate was 154 beats per minute, and his respiratory rate was 19 breaths per minute on admission. The initial diagnosis was diffused axonal injury, thoracic aortic injury, bilateral lung contusion with hemopneumothorax, liver injury, vertebral injury of T5, along with fractures of the right humerus, left patella, and bilateral scapula, and a stable pelvic fracture, with an injury severity score of 50. Brain magnetic resonance imaging on the 6th day showed diffused microbleeds in the bilateral subcortices, corpus callosum, and bilateral cerebellar hemisphere, consistent with diffuse axonal injury (Fig. 1). A stent-graft repair was performed for the aortic injury, on the same day. On the 10th, 12th, and 17th days, open reduction and internal fixations were performed to repair bone fractures.

After 2 weeks of admission, prolonged drowsiness persisted, and hyperthermia, tachypnea, tachycardia, hypertension, and hyperhidrosis without any specific stimuli were observed paroxysmally several times a day. PSH was diagnosed using the PSH-assessment measure [6].

One month after the injury, decreased joint mobility and progressive pain were evident. Computed tomography $(\mathrm{CT})$ showed $\mathrm{HO}$ in his humerus, ulna, radius, scapula, ilium, pubis, ischium, knee joint, patella, and tibia, as well as showing renal calculus (Fig. 2). To evaluate metabolic bone abnormalities, $25-\mathrm{OH}$ vitamin $\mathrm{D}$, parathyroid hormone, calcitonin, $\mathrm{N}$-terminal propeptide of type 1 collagen, and tartrate-resistant acid phosphatase $5 \mathrm{~b}$ were measured, revealing vitamin D deficiency (Table 1).

A bisphosphonate agent and vitamin D were administered for 1 month to prevent progressive $\mathrm{HO}$ and the significant discomfort associated with it. Thereafter, his symptoms, radiographic findings, and laboratory abnormalities improved. On the 55th day, he was transferred to another facility for rehabilitation.

\section{Discussion}

HO reportedly caused by hypercalcemia, tissue hypoxia, changes in sympathetic nerve activity, prolonged immobilization, and disequilibrium between parathyroid hormone and calcitonin [3]. It has also been shown that $\mathrm{HO}$ can be induced by fracture, burn, and neurological damage (brain injury and spinal cord injury) [7].

PSH was observed in approximately $10 \%$ of patients with severe traumatic brain injury [8]. HO occurred in $13.6 \%$ of patients with severe acquired brain injury, and
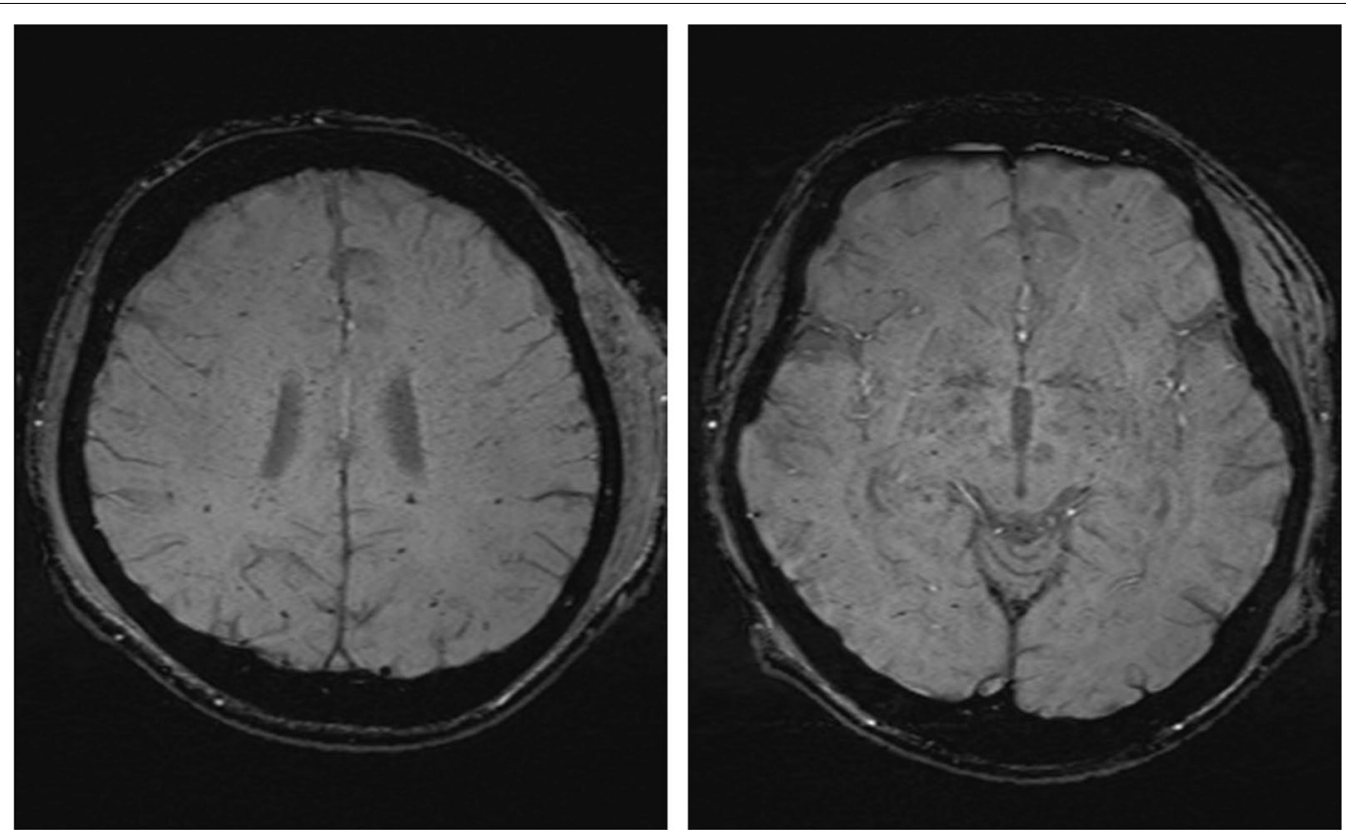

Fig. 1 Magnetic resonance images of the brain on the sixth day. Multiple micro-bleeding lesions are observed in the bilateral subcortex, corpus callosum, and bilateral cerebellar hemisphere with susceptibility-weighted images 
$\mathbf{a}$

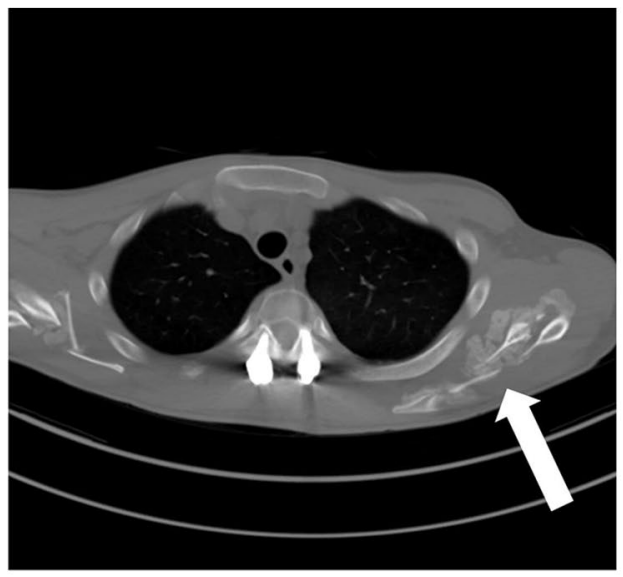

c

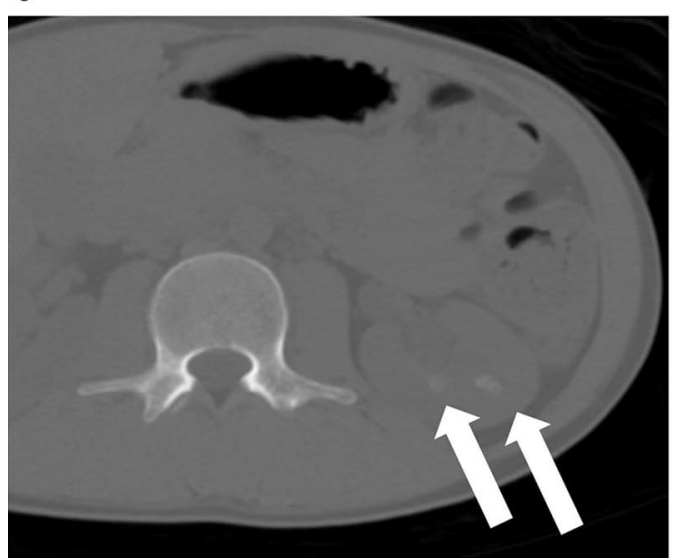

b

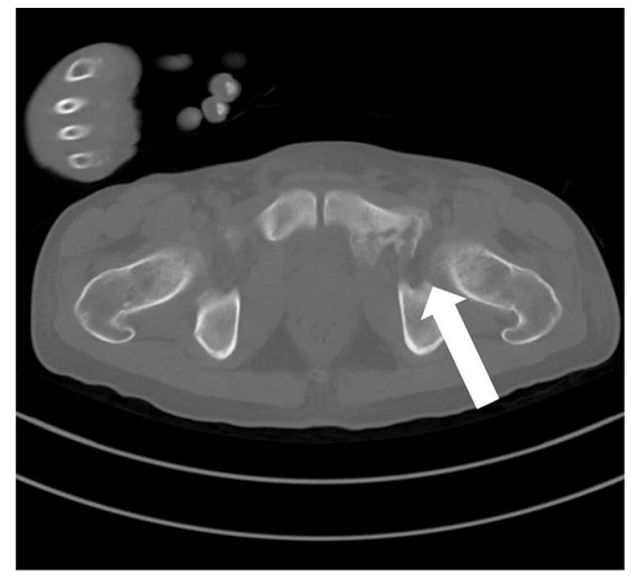

d

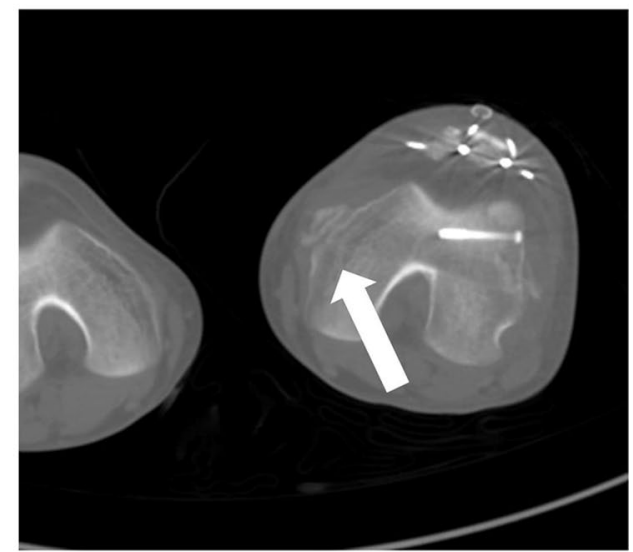

Fig. 2 Heterotopic ossifications on computed tomography. Heterotopic ossifications are observed in the scapula (a), pubis (b), tibia (c), and renal calculus (d; white arrows)

Table 1 Changes in bone metabolism parameters

\begin{tabular}{llll}
\hline & Reference range & 1 month & 2 months \\
\hline 25-OH-Vitamin D, ng/dL & $\geq 20$ & 9.5 & 17.0 \\
PTH, pg/mL & $14.9-56.9$ & 10.7 & 9.7 \\
Calcitonin, pg/mL & $0.5-6.16$ & $<0.5$ & $<0.5$ \\
P1NP, ng/mL & $18.1-74.1$ & 765.1 & 522.2 \\
TRACP-5b, $\mathrm{mg} / \mathrm{dL}$ & $170-590$ & 1687 & 457 \\
\hline
\end{tabular}

PTH parathyroid hormone, $P 1 N P$ procollagen type I N-terminal propeptide, TRACP- $5 b$ tartrate-resistant acid phosphatase $5 b$

a higher prevalence of $\mathrm{HO}$ was observed in male patients, younger patients, and those with PSH [9].

Few studies have sought to evaluate the relationship between vitamin D deficiency and $\mathrm{HO}$ in patients with $\mathrm{PSH}$. Although vitamin D deficiency is considered common and is associated with high morbidity and mortality in critically ill patients, there is no evidence that the administration of high-dose vitamin D has any advantage over a placebo with respect to 90-day mortality [10]. However, maintaining therapeutic serum vitamin D levels could reduce the risk of developing HO [11].

In this case, both parathyroid hormone levels and calcitonin secretions were controlled. These hormonal levels would not directly indicate a specific relation between $\mathrm{HO}$ and vitamin D deficiency. However, the improvement of $\mathrm{HO}$ after the administration of vitamin $\mathrm{D}$ and a previous report [11] might support the relation between $\mathrm{HO}$ and vitamin $\mathrm{D}$ deficiency. Therefore, this finding could contribute to the establishment of vitamin D administration as a therapeutic option in patients at risk of $\mathrm{HO}$.

\section{Conclusions}

$\mathrm{HO}$ in patients with PSH following severe head injury may be associated with vitamin $\mathrm{D}$ deficiency. Medications for vitamin-D-related metabolic abnormalities 
could also represent a novel treatment for this complex condition.

\section{Abbreviations}

PSH: Paroxysmal sympathetic hyperactivity; HO: Heterotopic ossification: P1NP: N-terminal propeptides of type 1 collagen; TRACP-5b:Tartrate-resistant acid phosphatase $5 b$.

\section{Acknowledgements}

The authors would like to thank to Editage (https://www.editage.jp/) for the English language review.

\section{Authors' contributions}

$\mathrm{TS}, \mathrm{MW}, \mathrm{YO}$, and TO performed the surgery and perioperative management on the patient. TS, MW, and SK drafted the manuscript. YO and TO helped to draft the manuscript. All authors read and approved the final manuscript.

\section{Funding}

None.

\section{Availability of data and materials}

All datasets supporting the conclusions of this article are included within the article.

\section{Ethics approval and consent to participate}

Consent to report was obtained from the patient and family. This article does not contain any studies with human or animal subjects performed by any of the authors.

\section{Consent for publication}

Written informed consent was obtained from the patient for the publication of the case report and all accompanying images.

\section{Competing interests}

The authors declare that they have no competing interests.

\section{Author details}

${ }^{1}$ Department of Emergency and Critical Care Medicine, Tohoku University Hospital Emergency Center, 1-1 Seiryo-cho, Aoba-ku, Sendai-shi 980-8754, Japan. ${ }^{2}$ Department of Graduate Medical Education Center, Tohoku University Hospital, 1-1 Seiryo-cho, Aoba-ku, Sendai-shi, Japan. ${ }^{3}$ Department of Orthopaedic Surgery, Tohoku University Hospital, 1-1 Seiryo-cho, Aoba-ku, Sendai-shi, Japan.

Received: 23 March 2020 Accepted: 23 September 2020 Published online: 23 November 2020

\section{References}

1. Perkes I, Baguley IJ, Nott MT, Menon DK. A review of paroxysmal sympathetic hyperactivity after acquired brain injury. Ann Neurol. 2010;68:126-35.

2. Bossche LV, Vanderstraeten G. Heterotopic ossification: a review. J Rehabil Med. 2005;37:129-36.

3. Shehab D, Elgazzar AH, Collier BD. Heterotopic ossification. J Nucl Med. 2002:43:346-53.

4. Baguley IJ, Perkes IE, Fernandez-Ortega JF, Rabinstein AA, Dolce G, Hendricks HT, et al. Paroxysmal sympathetic hyperactivity after acquired brain injury: consensus on conceptual definition, nomenclature, and diagnostic criteria. J Neurotrauma. 2014;31:1515-20.

5. Lucidarme O, Messai E, Mazzoni T, Arcade M, du Cheyron D. Incidence and risk factors of vitamin D deficiency in critically ill patients: results from a prospective observational study. Intensive Care Med. 2010;36:1609-11.

6. van Eijck MM, Sprengers MOP, Oldenbeuving AW, de Vries J, Schoonman GG, Roks G. The use of the PSH-AM in patients with diffuse axonal injury and autonomic dysregulation: a cohort study and review. J Crit Care. 2019;49:110-7.

7. Huang H, Wen-Xiang C, Yi-Ping H, Jian-Hai C, Zheng TZ, Zhang P. Relationship between heterotopic ossification and traumatic brain injury: Why severe traumatic brain injury increases the risk of heterotopic ossification. J Orthopaedic Transl. 2018;12:16-25.

8. Fernandez-Ortega JF, Prieto-Palomino MA, Garcia-Caballero M, GaleasLopez JL, Quesada-Garcia G, Baguley IJ. Paroxysmal sympathetic hyperactivity after traumatic brain injury: clinical and prognostic implications. J Neurotrauma. 2012;29:1364-70.

9. Bargellesi S, Cavasin L, Scarponi F, De Tanti A, Bonaiuti D, Bartolo M, et al. Occurrence and predictive factors of heterotopic ossification in severe acquired brain injured patient during rehabilitation stay: cross-sectional survey. Clin Rehabil. 2018;32:255-62.

10. The National Heart, Lung, and Blood Institute PETAL Clinical Trials Network. Early high-dose vitamin D3 for critically ill, vitamin D-deficient patients. N Engl J Med. 2019;381:2529-40.

11. Oleson CV, Seidel BJ, Zhan T. Association of vitamin D deficiency, secondary hyperparathyroidism, and heterotopic ossification in spinal cord injury. J Rehabil Res Dev. 2013;50:1177-86.

\section{Publisher's Note}

Springer Nature remains neutral with regard to jurisdictional claims in published maps and institutional affiliations.

\section{Submit your manuscript to a SpringerOpen ${ }^{\circ}$ journal and benefit from:}

- Convenient online submission

- Rigorous peer review

- Open access: articles freely available online

- High visibility within the field

- Retaining the copyright to your article

Submit your next manuscript at $\boldsymbol{\nabla}$ springeropen.com 